\title{
Control democrático del mercado
}

\author{
Hilton Tamayo ${ }^{1}$
}

En el artículo se traza una crítica a los postulados de Ludwig Von Mises, partiendo de la necesidad de la intervención de un tercer agente económico con poder controlador y regulador de la actividad económica. Se plantean los criterios de la teoría liberal de mercado y se contrapone con la realidad y los efectos del desequilibrio económico causado por la empresa. Por lo que se hace un recorrido de los principios keynesianos del equilibrio económico que marca la necesidad de una solución por medio de la intervención del gobierno rescatando al sistema económico.

This article presents a critical review of Ludwig Von Mises' postulates, starting from the need for a third economic agent to come into play to control power and to regulate the economic activity. The criteria of the liberal theory of the market are set forth in order to contrast the reality and the effects of the economic instability caused by business activity. Therefore, the article reviews the Keynesian principles of an economic balance that marks the need for a solution through the government intervention to rescue the economic system.

\section{INTRODUCCIÓN}

La crisis de los años treinta marcó un hito importante en la conducción económica de los países, especialmente los que se encontraban bajo el área de influencia de las economías de Estados Unidos y Europa occidental. La crisis obligó a plantear la intervención de los gobiernos en la economía y en el mercado, lo que desencadenó una serie de críticas sobre su acción respecto a los asuntos de la actividad productiva. El debate originó tanto posturas de apoyo como de crítica a la intervención del gobierno, dependiendo de la situación en la que se encontraba: de crisis o de superávit.

En la actual coyuntura del país el gobierno salvadoreño ha planteado un ambicioso plan "anticrisis"; se trata, en definitiva, de un claro aumento del gasto público en la inversión de carácter social, que eleve el ingreso y mejore el consumo. Con todo, cabe preguntarse si tales medidas, que requieren de una enorme recaudación de ingresos por parte de la administración pública, afectarán a los agentes de la economía en general. De hecho, ya comenzaron a plantearse una serie de cuestionamientos en la dirección antes mencionada. 
Pero, ¿Por qué la actuación del gobierno en la economía causa tanto miedo y recelo? ¿Qué hay detrás de esta conducta tanto de la clase media como de los grandes empresarios?

En la vida económica de una sociedad existen tres entes de vital importancia en su desarrollo económico: la empresa, la familia y el gobierno. Estos son los factores substanciales de la economía.

\section{La empresa.}

En el capitalismo la empresa tiene su lógica esencial: es la que proporciona los bienes o servicios que la sociedad en general demanda, tanto para su evolución como para su sobrevivencia. Esto, se conoce como "inversión privada", y su motivación es el lucro. De este modo, la empresa, tiene el poder en la toma de decisiones y el control de los medios de producción, especialmente de los recursos existentes en la sociedad.

La esencia liberal de la empresa tiene sus fundamentos en los postulados de Adam Smith. Postulados que fueron retomados y profundizados por Friedich Von Hayek y Ludwig Von Mises. De hecho el criterio acuñado por Jean Baptiste Say "que la oferta crea su propia demanda", tiene su fundamento último en la doctrina de Smith. Básicamente dicho criterio establece que:

"Un producto terminado ofrece, desde ese preciso instante, un mercado a otros productos por todo el monto de su valor. En efecto, cuando un productor termina un producto, su mayor deseo es venderlo, para que el valor de dicho producto no permanezca improductivo en sus manos. Pero no está menos apresurado por deshacerse del dinero que le provee su venta, para que el valor del dinero tampoco quede improductivo. Ahora bien, no podemos deshacernos del dinero más que motivados por el deseo de comprar un producto cualquiera. Vemos entonces que el simple hecho de la formación de un producto abre, desde ese preciso instante, un mercado de productos"

El desarrollo de la revolución industrial mostró el acelerado auge de empresas en diversas actividades económicas, que surgían y desaparecían rápidamente. Mostró también la consolidación de monopolios o estructuras oligopólicas que condujeron al dominio del mercado, socavando así el rol del Estado, reduciéndolo a acciones simples que favorecían los intereses de las empresas.

\section{Las familias y su fuerza de trabajo.}

Las familias, como segundo elemento importante de la actividad económica, son el demandante potencial y efectivo de la producción realizada por las empresas. Como agente económico, provee recursos al sistema en forma de

2. "Ley de Say”, http://www.eumed.net/cursecon/economistas/say.htm 
ahorro, que se traduce en recursos de inversión y provee la fuerza de trabajo requerida para la generación de productos finales. Esta doble función de las familias se explica a partir del concepto de apropiación originaria de capital y la consecuente división social del trabajo: en la sociedad unos se convierten en dueños de medios de producción y otros, la mayoría, en trabajadores que por "necesidad" venden su fuerza de trabajo a estas empresas.

Se trata de un contexto en el que la fuerza del trabajo se rige por la ley de la oferta y la demanda, los miembros económicamente activos de la familia ofrece su fuerza de trabajo y las empresas demandan dicha fuerza de trabajo. En definitiva, la fuerza de trabajo adquiere su valor de aquella ley, no obstante Marx piensa que:

"os equivocaríais de medio a medio, si creyerais que el valor del trabajo o de cualquier otra mercancía se determina, en último término, por la oferta y la demanda. La oferta y la demanda no regulan más que las oscilaciones pasajeras de los precios en el mercado."

La oferta y la demanda desde la perspectiva de Marx no es "más que las oscilaciones pasajeras de los precios en el mercado". Por ello, la retórica del punto de equilibrio nos plantea, que el valor de los bienes en el mercado se crea con la interacción entre oferente y demandante, pero en la realidad presenta únicamente la condición del valor en su fluctuación ante condiciones premeditadas que surgen por el sistema económico mismo:
"Supongamos que la oferta y la demanda se equilibren o se cubran mutuamente, como dicen los economistas. En el mismo instante en que estas dos fuerzas contrarias se nivelan, se paralizan mutuamente y dejan de actuar en uno u otro sentido. En el instante mismo en que la oferta y la demanda se equilibran y dejan, por tanto, de actuar, el precio de una mercancía en el mercado coincide con su valor real, con el precio normal en torno al cual oscilan sus precios en el mercado." 4

En la producción, requerir mano de obra implica un costo de inversión que los empresarios realizan para concretar la producción. Marx ${ }^{5}$ plantea que la remuneración dada al trabajador estaba ligada a un valor esencial que cubría los medios esenciales de vida 6 . En este punto, es necesario aludir a la concepción de Marx sobre la fuerza de trabajo como una mercancía, la que, en una situación de exceso de oferta, determina que:

3. Carlos Marx, "Salario, precio y ganancia”, http://www.marxists.org/espanol/m-e/1860s/65-salar.htm\#v 4. Ibíd.

5. “... suponemos, como ha venido haciéndose hasta aquí, que el valor de la fuerza de trabajo , o sea, la parte de la jornada de trabajo necesaria para la producción o conservación de la fuerza de trabajo, es una magnitud dada, una magnitud constante." MARX, El Capital, Tomo I, capitulo IX.

6. “... la suma de viveres y medios de vida habrá de ser por fuerza suficiente para mantener al individuo trabajador en su estado normal de vida y de trabajo”. Karl Marx, El Capital, Tomo I, capítulo IV. 
"el valor de la fuerza de trabajo se reduce al valor de una determinada suma de medios de vida"

Se opera un nivel de aumento de la mano de obra disponible, lo que origina un descenso en los salarios. En el mercado laboral la oferta de trabajo aumenta mientras la demanda permanece casi inactiva, o su crecimiento no se da en la misma proporción que el de la oferta, por ello aumenta la reserva laboral, se inicia un paro y por ende la desocupación.

La demanda laboral (empresario), ha presionado a la oferta laboral (trabajador) siempre. El acuerdo entre quien ofrece fuerza de trabajo y quien demanda fuerza de trabajo, se enmarca en las fluctuaciones que la misma demanda genera en el sistema; aprovechando condiciones tales como: aumento en la población trabajadora, analfabetismo e ignorancia, que limitan la acción de respuesta de la población para exigir sus derechos y, aunado a esto, prácticas monopólicas en el mercado, constituyen para la empresa mecanismos de aprovechamiento estratégico en la negociación, esa ventaja les lleva a establecer y mover el precio de la oferta de trabajo a niveles que les favorecen en su control de la mano de obra, el trabajador por el contrario debe ceñirse a aceptar sin miramientos el valor propuesto por sus capacidades.

El mayor garante del empleo en el sistema capitalista es la empresa privada, sin embargo su lógica es la reducción de costos. Esta situación de defensa operacional de las empresas se vuelve una reacción en cadena en todo el sistema ocasionando un proceso gradual en el incremento del paro.

¿Cómo surge una solución a esta condición? En la teoría liberal y neoliberal los ajustes se producen por el mismo sistema. Una libre actuación de las fuerzas del mercado lo vuelven a la estabilidad. En ciclos económicos cortos la reacción generalmente es adecuada por parte del mercado; pero en periodos largos la inestabilidad se traduce en más inestabilidad del sistema en todo el orden social, llegando a lo que se conoce como depresión.

No obstante, observemos una posible solución a la crisis económica actual en Estados Unidos desde la perspectiva de la teoría de Von Mises, según Keckeissen ${ }^{8}$ :

- Todos los valores de los activos que están pudriéndose en los balances de las instituciones financieras ha sido erradicados o al menos disminuidos hacia su valor real (ahora si valor)

7. Marx, El Capital, capítulo IV.

8. Keckeissen J. "El fin de la Crisis" artículo de la revista EMPRESA (revista académica de productividad y competitividad) FEPADE. Año 1, vol. 2 enero - junio 2009 ISSN 1998-636X. 
- Todas las burbujas que el previo y el actual diluvio de nuevo dinero fiat ${ }^{9}$ ha creado, han sido estalladas para que no den más sorpresas.

- Todos los altos precios y costos habrán caído para reflejar de nuevo una realidad creíble.

- Una sana bancarrota habrá suprimido todas las compañías que han sido presentadas como instituciones vibrantes, queriendo decir que todas las inversiones fantásticas (subprimes) ${ }^{10}$ sean eliminadas.

Resumiendo los puntos anteriores: la estructura de alivio y solución económica provendría de una situación natural de las relaciones económicas existentes. El planteamiento de esta situación es descrita por Keckeissen en las siguientes proposiciones de Von Mises:

- Nunca aumentar la cantidad de dinero.

- Nunca jugar con la tasa de interés del mercado.

- La deuda del gobierno es un ataque en contra del mercado libre.

- La bancarrota es la herramienta más segura para eliminar los errores del pasado.

- Las recesiones sirven principalmente para reducir los exagerados precios y costos.

- El mercado (cuando no hay asuntos de moralidad) ofrece la solución mejor y más rápida a los problemas económicos.

En la economía de mercado, según Mises, cada uno actúa para sí mismo pero con una intensión hacia la socialidad:

9. La palabra fiat significa hágase, en latín. Es dinero que existe por decreto del poder que gobierna. No tiene respaldo alguno, no promete entrega de algo de valor a su dueño; existe por decreto y por la fuerza del gobierno que impone ese decreto. Hoy en día, sólo existe dinero fiat en el mundo. El dinero fiat vale en el comercio, porque en el momento de su creación, sustituyo a otro dinero que sí era algo de valor, como en el caso del dinero real; o prometía algo de valor, en el caso del dinero fiduciario. Este dinero en cuenta de banco, es enteramente imaginario; sólo existe como una cantidad de unidades (unidades de nada, simples dígitos en una computadora) en una cuenta que lleva el nombre de uno o más dueños. Es prueba de la enorme fuerza de la imaginación humana que la mayor parte del dinero que existe en la economía es dinero en cuentas bancarias y su existencia es totalmente imaginaria. Existe sólo como dígitos pitagóricos. http://www.labolsa.com/foro/ mensajes/1126367098/

10. Una hipoteca subprime es una modalidad crediticia que se caracteriza por tener un nivel de riesgo superior a otros préstamos que ofrecen las instituciones bancarias, ya que se dedican a otorgar créditos hipotecarios a personas que presentan un alto riesgo, por esa razón las empresas subprime aseguran su inversión por medio de altos intereses o del embargo de la propiedad que implica la hipoteca. http://mx. finanzaspracticas.com/1782Que-es-una-hipoteca-subprime.note.aspx 
"en sistema social de la división del trabajo y la propiedad privada de los medios de producción cada uno actúa para sí mismo; pero las acciones de todos persiguen la satisfacción de las necesidades de los demás, tanto como la satisfacción de las propias"11

Y describiendo al mercado como:

"un proceso que lo mueven las acciones de los diferentes individuos que cooperan en el sistema de la división del trabajo (...). El proceso del mercado es la adaptación de las acciones individuales de los diversos miembros de la sociedad de mercado, a las exigencias de la cooperación mutua. Los precios de mercado le dicen a los productores qué deben producir, cómo hacerlo y cuánto deben producir"12

En la idea de la cooperación que Mises pregona, ¿quiénes son los cooperantes? Pretende establecer que sólo las habilidades personales determinarán que unos se sobrepongan a los otros en la "competencia social”13; el más apto logrará el beneficio esperado. En esta lógica, al haber una diversidad de actividades económicas, sólo aquéllas de la misma índole se encontrarán en una disputa sobre quién provee mejor los satisfactores al resto de los miembros de la sociedad.

Los dueños de los medios de producción, es claro promueven y ejecutan la cooperación, pero el trabajador y consumidor sólo es catalizador con su ingreso de la tal "cooperación social".

¿El trabajador es consciente del "proceso de cooperación"? El trabajador integra, forzosamente, las actividades que le permiten obtener un ingreso que cubra los medios de vida esenciales de subsistencia. Esta situación para Marx es producto de la separación del productor directo de su medio de producción, lo que produce la enajenación del trabajo y el sujeto únicamente puede aspirar a su subsistencia. La alternativa que le queda es ofrecer su fuerza de trabajo en la unidad productora que mejor le provea los medios de vida requeridos. La cooperación es, por tanto, forzada e irremediable. En este caso, al trabajador dentro del sistema económico capitalista, no le queda otra opción que dirigir sus ingresos a los elementos que le provean en el proceso de producción. El sistema en sí le determina qué debe consumir y no lo que el trabajador en libertad pueda escoger.

La cooperación es válida entre los productores, siempre y cuando ninguno altere el carácter de armonía y equilibrio del sistema.

11. Von Mises Ludwig, El mercado, publicaciones Universidad Francisco Marroquin, Guatemala, 1985, pág. 7.

12. Óp. Cit. Pág. 9.

13. Óp. Cit. Pág. 44. 
Pero basta una acción especulativa para turbar el equilibrio de mercado y provocar irremediablemente una recesión en la economía. En el capitalismo, el centro principal de su auge y desarrollo se encuentra en la actividad económica financiera, que abarca las transacciones bancarias y el mercado de valores. Si hay colapso en estas áreas, la recesión pasa a una crisis generalizada. Por ejemplo, la crisis de los 30's comenzó con una sobreproducción en el sistema y la incapacidad de éste para absorberla, se prolongó cuando en la "Bolsa de Valores" los "títulos valores" comienzaron a perder valor y el precio se desplomó lo que llevó a una reacción en cadena afectando a otros mercados bursátiles. En la crisis del 2008 fue la falta de liquidez en el sistema financiero, por el aumento de las hipotecas de alto riesgo (subprimes), lo que condujo a un alto riesgo especulativo en las diferentes Bolsas del mundo.

¿A qué solución recurre entonces el mercado? Siguiendo los postulados de Von Mises, el mercado, para lograr el equilibrio, produce una serie de bancarrotas a la espera de una mejoría parcial y gradual. Pero aquí ocurre la contradicción a la anterior teoría, si bien "la bancarrota es la herramienta más segura para eliminar los errores del pasado", la actitud de los empresarios corre bajo otra lógica básica: la retracción de la inversión en la espera de una mejoría futura, al retraerse la inversión se amplían aun más los efectos de la crisis, ya que el empresario limita la inversión en actividades económicas más seguras y reduce los costos. Mientras tanto aumenta el paro laboral, se reduce el ingreso de las familias, se pierde la capacidad de compra en general, aumentan los precios y toda una serie de efectos contraproducentes en la estabilidad del sistema. Esta situación responde a la más estricta racionalidad empresarial. De lo único que se trata es de salvaguardar sus recursos ante el impacto de la crisis.

\section{Papel del gobierno.}

La variación de la inversión está en función del ahorro que las familias realizan, el ahorro es posible por el ingreso que se recibe en forma de salarios. La ganancia del capital proviene del consumo. El consumo puede verse afectado: por un cambio en el salario y por la flexibilidad laboral. Si el consumo es afectado, se afecta toda la cadena productiva, se afecta la inversión. Por lo tanto urge preguntarse ¿quién debe evitar las disparidades que presenta el mercado, en cuanto a la regulación del ingreso necesario que incentive la inversión? Es evidente que tiene que provenir no desde dentro del mercado mismo, sino que es necesaria la intervención de un tercero, que para Keynes era claro que quien lo podía ejercer es el gobierno. El gobierno debe ser quien logre el nivel de equilibrio en el mercado. Desde la perspectiva de Keynes, su regulación es transitoria, hasta conseguir los niveles deseados y dejar funcionar la economía en su cause normal.

Sin embargo esto no significa que la intervención del gobierno esté exenta de dificultades ¿por qué falla el gobierno en este cometido? 
Dejando a un lado la creencia popular sobre la inefectividad de la administración pública, tenemos que analizar a los gobiernos en los sistemas capitalistas.

En el capitalismo los gobiernos son elegidos en un proceso de votaciones en el que la mayoría de votantes eligen a sus representantes. Hasta aquí podemos decir que se trata de un principio democrático, ya que se deja a las familias elegir a sus dirigentes.

No obstante, los gobiernos elegidos distan mucho de defender los intereses generales y con frecuencia anteponen intereses particulares, esto es, a favor de minorías de privilegio económico o político.

Los gobiernos que representan los intereses económicos (partidos políticos de derecha o conservadores $)^{14}$, por lo general, obedecen a una cúpula empresarial a la cual favorecen en el desarrollo de leyes e incentivos al capital, profundizando en muchos casos la desigualdad en la distribución del ingreso.

Los gobiernos que representan los intereses populares (partidos políticos de izquierda o liberales), se observan dos reacciones opuestas, los representantes elegidos se inclinan hacia el desarrollo de políticas y leyes restrictivas del desarrollo de la libertad del capital, sin llegar al cambio de sistema económico, o se vuelven permisivamente corruptos y favorecen los intereses de quienes devuelven beneficios por favores concedidos.

En todo caso, las formas anteriores de gobierno, no contribuyen al equilibrio de la economía de mercado; y por el contrario, favorecen su inestabilidad.

Lo que si queda claro, es que un gobierno que hereda una crisis económica debe poner en marcha una serie de políticas de carácter económico, que van a afectar, en alguna medida, a un sector que no verá con buenos ojos tal intervención.

Los gobiernos que en alguna medida tratan de crear una conducta equilibrada del mercado se exponen a una serie de críticas debido a sus políticas de aumento del "gasto público"15.

Durante la crisis de los 30's, el "new deal"16 fue duramente criticado por una serie

14. Utilizamos aquí el concepto de partidos políticos de derecha o conservadores, que representan los intereses de los dueños de los medios de producción; y de izquierda o liberales, que representan los intereses de los trabajadores o los sectores populares.

15. Keynes propone es aumentar el gasto público $(G)$, de forma que aumentando el gasto publico se aumente el empleo el cual a su vez vuelva a crear empleo hasta volver a alcanzar otro punto de equilibrio. http://www. elblogsalmon.com/mundo-laboral/que-es-el-modelo-keynesiano

16. New Deal (literalmente en castellano: “Nuevo Trato") es el nombre dado por el presidente estadounidense Franklin D. Roosvelt a su política intervencionista puesta en marcha para luchar contra los efectos de la Gran Depresión en Estados Unidos. Este programa se desarrolló entre 1933 y 1938, con el objetivo de mantener a las capas más pobres de la población, de reformar los mercados financieros y de re dinamizar una economía estadounidense herida desde el crack del 29 por el desempleo y las quiebras en cadena.

http://www.america.gov/st/educ-spanish/2008/September/20080916145341pii0.9690821.html 
de políticas de carácter social que constituyó el comienzo de la intervención del gobierno para revertir los problemas ocasionados por la distorsión del mercado. Una buena parte de las críticas a estas acciones derivaban del hecho de considerar al gobierno incapaz e ineficiente en el manejo de la economía, algunas objeciones a este trato las presenta Jim Powell ${ }^{17}$ :

- El Estado no puede crear un crecimiento sostenido y trabajos productivos

- Es simplista imaginarse que la intervención del gobierno en una economía compleja funcionará como se pretende.

- Los trabajos gubernamentales no ayudan a la gente a desarrollar valores y habilidades que se necesitan en el sector privado.

No obstante, la propuesta de intervención del gobierno proviene del análisis que John Maynar Keynes hizo de los ciclos económicos.

"pues bien, indica la importancia vital de establecer ciertos controles centrales en asuntos que actualmente se dejan casi por completo en manos de la iniciativa privada (...) El Estado tendrá que ejercer una influencia orientadora sobre la propensión a consumir (...) Creo, por tanto, que una socialización bastante completa de las inversiones será el único medio de aproximarse a la ocupación completa; aunque esto no necesita excluir cualquier forma, transacción o medio por los cuales la autoridad pública coopere con la iniciativa privada. Pero fuera de esto no se aboga francamente por un socialismo de Estado que abarque la mayor parte de la vida económica de la comunidad. No es la propiedad de los medios de producción la que conviene al Estado asumir"18

En el concepto dinamizador de Keynes, el gobierno (Estado) debe cumplir la labor de catalizador de la economía, cuando la lógica empresarial asume su postura básica de reducción de los costos y los riesgos; ello origina una reacción en cadena, que crea efectos más devastadores de la actividad económica.

El mecanismo al cual el gobierno recurre para activar la economía es el "gasto público". Éste es de orden presupuestal, en tanto considera los gastos del aparato estatal en un año de operaciones. Las formas de aprovisionamiento de recursos monetarios de éste se verifican a través de la captación de impuestos o del endeudamiento (éste último supone la venta de bonos o préstamos a entidades internacionales); en todo caso, son medidas que generan duras críticas de parte de las entidades empresariales.

17. Jim Powell, “El mito de Roosevelt y su Nuevo Trato”, http://www.elcato.org/node/359

18. Keynes John, Óp. Cit. pág. 369 
Incrementar el presupuesto supone realizar inversión social, lo cual se reflejará en la economía, con acciones directas o indirectas, por ejemplo, un proyecto de generación de viviendas para familias con ingresos menores del salario mínimo. Esto presupone, que el gobierno recurrirá a la empresa privada en la realización de tales proyectos y que las empresas constructoras van a recibir ingresos por una determinada cantidad de proyectos habitacionales, lo que a generar empleos directos e indirectos en la realización de los mismos.

En la crisis financiera del 2008 el gobierno de Estados Unidos estableció políticas de estímulo a la economía, comprando los títulos "subprimes" y, rescatando así empresas en quiebra. Al mismo tiempo, llevó a cabo, un alto estímulo a la economía por medio del gasto público en proyectos de inversión social. Lógicamente, esto tiene sus repercusiones: el Estado tuvo que elevar su presupuesto jugando con la política monetaria y con el endeudamiento para la realización del rescate de empresas, en su intento de evitar caos financiero y detener el desempleo.

Desde el punto de vista de Paul Krugman, premio Nobel de Economía en 2008:

"los paquetes de estimulo han funcionado y estos obedecieron en buena parte y en distintos países a las ideas de inversión en obras públicas, como medio de crear empleo en épocas de crisis, de acuerdo con la filosofía del economista británico John Keynes con lo cual se afirma que las políticas keynesianas funcionan." 19

En el caso salvadoreño, la crisis mundial se ha mezclado con una crisis interna. La política gubernamental siempre ha tenido una fuerte injerencia de índole partidista en la economía. Los resultados han sido: la pérdida de actividades productivas específicas, aumento inflacionario, alto índice de migración hacia el exterior y aumento del desempleo.

La implementación de medidas neoliberales ha sido paradójica: por un lado, se defiende la no injerencia del gobierno en la economía y, por otro laso, se ha requerido, en muchos casos, de la intervención debido a las diferentes coyunturas económico-sociales. Por ejemplo, el período de posguerra de 1992 a 1994 fue una etapa de reconstrucción de la infraestructura dañada durante la guerra civil de los 80 's e incentivación de la inversión en actividades productivas llegando a un crecimiento del 6\% aproximadamente. Durante el período de 1994 hasta la fecha se ha pasado por recesiones y crisis económicas muy fuertes que han requerido la pronta intervención del Estado, los desastres naturales que han destruido aun más el tejido productivo agrario del país han requerido, asimismo, la intervención del gobierno. 
Se han sucedido así políticas económicas diversas con una fuerte intervención del Estado, como la ley de integración monetaria, reformas fiscales, eliminación de la regulación monetaria, así como otras. Todas han sido iniciativas gubernamentales bajo el supuesto de beneficio a la economía nacional. En tal sentido, el Estado no puede abstraerse de la economía y convertirse en un simple agente consumidor, por el contrario, es y tiene que ser un actor dinámico en la economía diaria de cualquier sociedad.

\section{Conclusión}

En la realidad económica el Estado nunca ha estado ausente del quehacer económico. Lo que genera las discusiones sobre su actuación es la forma de gobierno existente en un ciclo económico especifico.

Una administración pública demasiado controladora coarta la iniciativa productiva; y una demasiado permisiva conlleva a irregularidades excesivas de mercados de competencia imperfecta, generando conductas acaparadoras o monopólicas de las actividades productivas.

Pretender que el Estado no participe en la economía es una ilusión o aspiración puritana de los teóricos clásicos, pero pretender un control total ejercido por gobierno es también un craso error.

En la lógica del capitalismo, en una actividad económica el beneficio que prima es la obtención de la satisfacción entre los actores que representan la relación de comprar y vender. Cada uno es consciente de lo que busca y conoce racionalmente sus expectativas en cuanto al manejo de la relación comercial. El demandante posee una fuerza de negociación en base a su poder de compra según sus ingresos, pero es débil en la línea de generar un bloque con otros consumidores. Con todo, sí bien se dice que su poder está centrado en su capacidad de tomar decisiones, según Mises:

"Los consumidores son quienes realmente determinan no sólo los precios de los bienes de consumo sino los precios de todos los factores de la producción. Ellos determinan los ingresos de todos los miembros de la economía de mercado (...) De manera que los dueños de los factores materiales de producción son prácticamente los fiduciarios de los consumidores, nombrados o destituidos por medio de una elección que se repite todos los días" 20 
Estudiemos la siguiente metáfora que nos presenta Mises.

"Un 'rey de los chocolates' no tiene ningún poder sobre los consumidores, sus clientes. Él les da el chocolate de la mejor calidad, al precio más bajo. Él no gobierna a los consumidores sino que los sirve. Los consumidores no están atados a él. Ellos tienen la libertad de comprar o no en sus tiendas. Él pierde su 'reino' si los consumidores prefieren gastar sus centavos en otro sitio"21

En la metáfora, el rey no es rey, es un simple servidor que espera pacientemente la llegada de un cliente el cual tiene la libertad de aceptar o no su producto ${ }^{22}$.

Pero, ¿entre cuántos oferentes, entre cuántos productos existentes tendría que elegir el consumidor? El consumidor valora la calidad en función de la experiencia acumulada y comparada, es decir, no es éste el que reconoce de por si la calidad sino que es planteada en el ambiente social en el cual se desarrolla, el empresario manipula subjetivamente las valoraciones que expone deliberadamente al consumidor por medio de diferenciaciones especificas sobre el producto a vender, a inicios de la industrialización la imposición sobre los clientes era tajante, veamos la siguiente cita:

"Se dice que cuando alguien le sugirió a Henry Ford que ofreciera el Modelo T (1908-1927) en diferentes colores, su respuesta fue: 'Lo pueden pintar de cualquier color, siempre que sea negro'"23

El famoso "modelo T" revoluciono el transporte en su país estableciéndolo como el vehículo para el ciudadano común, las características eran similares en todos los automóviles de la época, hasta que los competidores de Ford, comenzaron a producir nuevos modelos con diferencias subjetivas creando un atractivo psicológico sobre el cliente, de ahí el manejo de una necesidad clara a una manipulación de los deseos en el sujeto hasta el día de hoy.

Para que el consumidor desarrolle una voluntad consciente, debe ser protegido y educado, esto se logra si el gobierno ejerce un rol preventivo con sus instituciones de educación y defensa de los intereses generales, con lo cual se convierte en un árbitro que vele por que las reglas favorezcan a ambos agentes económicos.

21. Von Mises Ludwig. Óp. Cit. pág. 41

22. Se plantea el supuesto que un producto como el chocolate es homogéneo a otros que produzcan otros chocolateros y que no existen mayores diferencias sobre las cuales se incida en la voluntad de un comprador. 23. Alle Alejandro, El Diario de Hoy, editorial publicado el 25 de octubre de 2005, "De cualquier color..., siempre que sea negro" http://www.elsalvador.com/noticias/2005/10/25/editorial/edi3.asp 


\section{Bibliografía}

Keynes, J., (1943), “Teoría general de la ocupación, el interés y el dinero" ( 1 edición), Fondo de Cultura Económica, México.

Marx, C. (1979), El capital (critica de economía política), ( $2^{\circ}$ edición), Fondo de cultura económica, México.

Mises, Ludwig, (1985), El mercado, (1 $1^{\circ}$ edición), Publicaciones de la Universidad Francisco Marroquin, Guatemala.

Trujillo, Antonio, (2009), "Keynes tenía razón”, El economista, año 4, N8 83, pp. $92-94$

Keckeissen, J., (2009), "El fin de la crisis", Empresa (revista académica de productividad y competitividad, FEPADE), año 1, vol. 2, pp. 7-22.

Universidad de Malaga, Enciclopedia y biblioteca virtual de las ciencias sociales, económicas y jurídicas, http://www.eumed.net/

Trujillo Antonio, “Keynes tenía razón, revista "EL ECONOMISTA” 2009, año 4, \# 83. 